\title{
CHANGING CORPORATE CULTURE TO IMPROVE BUSINESS PERFORMANCE: CASE OF THE AUSTRALIAN AUTOMOBILE INDUSTRY
}

\author{
Clark Li Ke YOU, \\ Max COULTHARD, \\ Sonja PETKOVIC-LAZAREVIC, \\ Monash University, Australia
}

\begin{abstract}
Literature suggests that by developing distinctive cultural traits of involvement, mission, consistency and adaptability, firms can achieve effective business performance. Whilst this topic has been researched worldwide, little research has been done in Australia. This paper helps fill this gap in the literature using the automobile industry. The research findings suggest that a link between corporate cultural traits and business performance exists in the Australian automobile industry. Compared to other cultural traits, adaptability has the greatest influence over business performance. Of the business performance measures assessed, both non-financial and financial, customer satisfaction as a non-financial measure was considered the most important one. In comparing cultural traits and business performance, consistency and mission were found to be important predictors of profitability; and adaptability and mission important predicators of sales growth.
\end{abstract}

Keywords: Cultural traits, Adaptability, Consistency, Customer satisfaction

\section{INTRODUCTION}

This paper looks at the influence of corporate cultural traits on business performance in the Australian automobile industry undergoing rapid change. The aim is to identify traits that may enhance business performance and lead to a sustainable competitive advantage.

For decades, researchers have assessed the influence of corporate culture on the management style within organisations and how this affects employee performance (Lee \& Yu, 2004). For Hsu et al., (2009) leadership style, organisational culture, and especially organisational learning have an impact on organisational performance. Denison et al., (2003) go further suggesting that corporate culture may be one of the most powerful tools to be used to improve business performance. Although few studies have tested the value of corporate cultural traits during periods of rapid change, Singh (2006) identified that organisations with a highly adaptive corporate culture can actively respond in a changing environment and capture market opportunities.

Corporate culture can be characterised through employees' values, beliefs and their behaviour within the organisation (Petrovic-Lazarevic, 2006; Singh, 2006). This study used the corporate cultural traits of consistency, mission, involvement, and adaptability, developed by Denison et al. (2003). Accordingly, cultural traits are defined as follows:

Consistency characterises the organisation's core values; methods used to achieve agreement; and the coordination and integration systems that hold the company together (Denison et al., 2003). Cultural consistency improves business performance by creating coordination from top level management to first line employees (Mavondo \& Farrell, 2003).

Mission describes the strategic direction and intent an organisation is aiming to achieve; its goals and objectives; and its vision. Hence, employees who have a clear mission in their mind can significantly improve their own productivity (Buckingham, 2005). 
Involvement covers the level of staff empowerment in decision making; its team orientation; and the capability development undertaken by the organisations. It is used to measure the company's ability to drive commitment and develop ownership with employees (Denison et al., 2003; Rotenberry \& Moberg, 2007).

Adaptability measures the company's ability to read and scan the business environment and to respond to change (Denison et al., 2003). Organisations that have an adaptable culture tend to both actively and openly receive and interpret opportunities and threats from the external environment, responding to these external signals appropriately (Pennington, 2003). An adaptive culture encourages and supports employees to improve their ability by learning from day-to-day tasks (Denison et al., 2003).

Some authors focus on financial measures of business performance (Allen \& Helms, 2002). In this respect, financial indicators usually include profit, efficiency trend, sales trend (Kloot, 1999), return on investment (Kennerley \& Neely, 2003) and market share (Bloodgood \& Katz, 2004).

Concept of corporate sustainability, comprising company's activities that demonstrate inclusion of social and environmental concern in business operations and in interactions with stakeholders (van Marrewijk \& Werre, 2003), is recently introduced as a measure of sustainable business performance. Findings by Hubbard (2009), Johnson (2009), Robert (2000), and Scholten (2009) suggest that corporate sustainability may assist organisations in the long run as it has a positive impact on corporate performance. One key sustainable non-financial indicator considered important is customer satisfaction (Vukmir, 2006).

The Australian automobile industry was chosen for this study because it is a key sector in the Australian economy. Exports now account for around 40 percent of domestic motor vehicle production. The industry's domestic value added component total is over AUD \$5.6 billion and 5.6 percent of the total Australian manufacturing sector (Department of Foreign Affairs and Trade, 2008). Since free trade agreements between Australia and other nations have been signed, the Australian automobile industry is gradually moving towards a more open trading environment with low levels of government protection. This new competitive environment has lead to significant job shedding within the industry, in particular within the automotive component manufacturer and retail sector.

To minimise further job losses, maintain viability, and above all help the Australian economy to overcome the present global economic crisis, the Australian automobile industry should improve its business performance. One of the ways in which this may be achieved is through developing a performance oriented corporate culture. Dealing with this matter, this paper is organised as follows: after the methodology, we present and discuss the project results, followed by concluding remarks and future research interests.

\section{METHODOLOGY}

A multi-method study based on quantitative research was chosen for better understanding of data and an in depth and valid analysis of research findings (Creswell, 2003) relevant to the automotive industry in Australia. This paper focuses on the quantitative results of a questionnaire used to survey both manufacturers and retailers in this industry.

We have used the Australian Bureau of Statistics (2002) measure for business size, by employees: small business 1-19; medium business 20-199; and large business 200 plus employees. A quantitative approach has been applied based on the Denison Organisational Culture Survey (Denison \& Neale, 1996). The survey measured twelve indices of organisational culture (See Table 1) using five questions for each index, a total of 60 questions. For all items a five-point Likert scale with response categories ranging from strongly disagree to strongly agree was applied. The twelve indices were used to measure four main cultural traits: involvement, consistency, adaptability and mission. Table 1 outlines these four cultural traits.

The survey also sought senior executive's perception of organisational performance on the following 
variables: net profit, customer satisfaction, market share, return on investment, efficiency trend, and sales trend. Chief executive officers and/or general managers were chosen as the preferred research subjects to complete the questionnaire as they were seen to be best placed to comment on the organisation's corporate culture. The interviewees were further divided into two groups: high performing organisations versus low performing organisations; the criterion used is based on the summated mean of the six performance measures used (See Table 2). Thus, high performing organisations have summated mean of the six performance measures used in this study above 22.51, while low performing organisations have summated mean below 22.51 This process helped identify key differences in cultural traits and their potential influence on organisational performance. It also allowed differences between small to medium organisations and large organisations to be assessed.

The selection of the organisations, to create a mailing list, was based on three main sources: Membership list of the Federation of Automotive Products Manufacturers; Australian Automotive Aftermarket Association - Exporters Directory; and Registered Automotive Retailers from the telephone directory-Yellow Pages. 250

\section{Table 1. Four Cultural Traits and Indices of Organisational Culture}

\begin{tabular}{|l|c|c|c|c|}
\hline \multicolumn{2}{|l|}{ Cultural Trait } & \multicolumn{3}{|c|}{ Indices of Organisational Culture } \\
\hline 1 & Involvement & Empowerment & Team Orientation & Capability Development \\
\hline 2 & Consistency & Core Value & Agreement & Coordination and Integration \\
\hline 3 & Adaptability & Creating Change & Customer Focus & Organisational Learning \\
\hline 4 & Mission & Strategic direction and Intent & Goals and Objectives & Vision \\
\hline
\end{tabular}

organisations were selected in total for this project. Eighty useful questionnaires were returned and analysed using SPSS for Windows 15.0. All measures were aggregated at the organisational level.

\section{Table 2. Breakdown of Surveyed Organisations Based on Employee Size and Performance}

\begin{tabular}{|c|c|c|}
\hline Performance & Small to Medium organisations & Large Organisations \\
\hline Hi & 42 & 0 \\
\hline Low & 31 & 7 \\
\hline Total & 73 & 7 \\
\hline
\end{tabular}

\section{LIMITATIONS}

In our research, we used self-report survey data that may be affected by leniency or inflated responses. If the actual performance measures were available in the public domain as it was not the case, we could have achieved greater accuracy in our findings. Further, we did not use multiple responses within each organisation, thus we could not reduce perceptual bias. Finally, we collected data at a single point in time that does not allow for changes in perceptions and attitudes over time. A longitudinal study on organisational culture would be more appropriate.

\section{DISCUSSION OF RESULTS}

A survey response rate of 25 percent or more is considered as satisfactory (Sellitto, 2006); the survey response rate for this project was 32 percent. Based on the demographic data, three groups were identified: manufacturer (51 percent), retailer (46 percent) and others (three percent). Of these respondents, 34 percent of the organisations had been operating less than 10 years and 66 percent over 10 years. The majority of organisations were subsidiaries of overseas organisations (48.5 percent), another 44 percent were privately owned domestic organisations, and 7.5 percent publicly owned domestic organisations. About 54 percent of respondents were in general management position, while the rest of respondents were either chief executives officers (14 percent) or lower 
level managers and specialists (32 percent).

Reliability test results measured by Cronbach's alpha are presented in Table 3.

According to Liu and Zumbo (2007), a Cronbach's alpha of 0.70 and above is an acceptable reliability coefficient. Hence, as all the summated measures used to assess business performance and cultural traits in this study were above 0.70 , they were treated as reliable.

\section{Table 3. Cronbach's Alpha Analysis for Major Variables}

\begin{tabular}{|c|c|}
\hline & Cronbach's alpha \\
\hline Business performance measures & 0.83 \\
\hline Involvement & 0.91 \\
\hline Consistency & 0.89 \\
\hline Adaptability & 0.88 \\
\hline Mission & 0.93 \\
\hline
\end{tabular}

\section{Business Performance}

Statistical analysis of the questionnaires identified that all four cultural traits influence business performance, confirming the findings of Denison et al. (2003).

The first step undertaken was to assess respondent's opinions on the impact of cultural traits on business performance. Although respondents overall considered all traits important, there were some differences with consistency (mean 3.99) scoring the highest, while adaptability (mean 3.92) scoring the lowest of corporate cultural traits (See Table 4).

\section{Table 4. Respondents' Opinions as to the Importance of Corporate Cultural} Traits to Business Performance

\begin{tabular}{|c|c|c|c|c|c|}
\hline & & Involvement & Consistency & Adaptability & Mission \\
\hline \multirow{2}{*}{$\mathrm{N}$} & Valid & 80 & 80 & 80 & 80 \\
\cline { 2 - 6 } & Valid & 0 & 0 & 0 & 0 \\
\cline { 2 - 6 } & Valid & 3,98 & 3,99 & 3,92 & 3,97 \\
\hline
\end{tabular}

Overall, respondents considered all performance measures important, though there were different values placed on each measure (See Table 5). For example, some respondents felt traditional financial measures

Table 5. Business Performance Measures

\begin{tabular}{|l|c|c|}
\hline & Mean & SD \\
\hline Financial measures & & .839 \\
\hline Net Profit & 3.68 & .707 \\
\hline Customer Satisfaction & 3.86 & .907 \\
\hline Market Share & 3.75 & .938 \\
\hline Return on Investment & 3.68 & .758 \\
\hline Efficiency Trend & 3.79 & .903 \\
\hline Sales Trend & 3.76 & \\
\hline Non-financial measures & & .707 \\
\hline Customer Satisfaction & 3.86 & \\
\hline
\end{tabular}


were not as important as the non-financial measure of customer satisfaction. Respondents ranked net profit (mean= 3.68) and return on investment (mean $=3.68)$ the lowest, followed by, in ascending order, market share (mean 3.75) sales trend (mean 3.76) efficiency trend (mean 3.79) and customer satisfaction the highest (mean 3.86). This suggests a belief that customer satisfaction is a precursor to achieving financial objectives.

We further studied strength of the relationship between the four cultural traits and business performance in Australian automobile organisations using correlation analysis (See Table 6). This confirmed the opinions of respondents that all four cultural traits have a strong relationship with business performance as all achieved $\mathrm{r}>0.5$ level. Adaptability had the strongest relationship with business performance $(\mathrm{r}=0.573)$; followed by involvement $(\mathrm{r}=0.505)$, mission $(\mathrm{r}=0.510)$. The regression analysis identified that those traits that really improve performance are the exact opposite to the traits respondents perceive as important.

\section{Table 6. Correlation Analysis between Four Cultural Traits and Business} Performance

\begin{tabular}{|r|l|l|l|l|l|}
\hline & Variables & 1 & 2 & 3 & 4 \\
\hline 1 & Business Performance & & & & \\
\hline 2 & Involvement & $.505^{* *}$ & & & \\
\hline 3 & Consistency & $.545^{* *}$ & $.761^{* *}$ & & \\
\hline 4 & Adaptability & $.573^{* *}$ & $.720^{* *}$ & $.721^{* *}$ & \\
\hline 5 & Mission & $.541^{* *}$ & $.779^{* *}$ & $.817^{* *}$ & $.757^{* *}$ \\
\hline$* * p$ & \multicolumn{5}{|l}{} \\
\hline
\end{tabular}

A breakdown of the components of each of the cultural traits identified that the key variables with the greatest relationship with business performance were creating change $(\mathrm{r}=0.652)$, team orientation $(\mathrm{r}=0.532)$, strategic direction and intent $(\mathrm{r}=0.525)$, and core value $(\mathrm{r}=0.503)$ (See Table 7).

\section{Table 7. Correlation Analysis between all Cultural Trait Indices and Business Performance}

The findings suggest that automotive organisations in turbulent times may increase their organisational performance with more attention to adaptability attributes (being customer focused,

\begin{tabular}{|c|c|c|c|c|c|c|c|c|c|c|c|c|c|c|}
\hline \multirow[t]{2}{*}{ Cultural Traits } & \multicolumn{2}{|c|}{ Variables } & \multirow[t]{2}{*}{1} & \multirow[t]{2}{*}{2} & \multirow[t]{2}{*}{3} & \multirow[t]{2}{*}{4} & \multirow[t]{2}{*}{5} & \multirow[t]{2}{*}{6} & \multirow[t]{2}{*}{7} & \multirow[t]{2}{*}{8} & \multirow[t]{2}{*}{9} & \multirow[t]{2}{*}{10} & \multirow[t]{2}{*}{11} & \multirow[t]{2}{*}{12} \\
\hline & 1 & B usiness Performance & & & & & & & & & & & & \\
\hline \multirow[t]{2}{*}{ Invo vlement } & 2 & Empowerment & $0.497^{\text {*** }}$ & & & & & & & & & & & \\
\hline & 4 & Capability Development & $0.276 *$ & $0.430^{\text {*** }}$ & 0.512 ** & & & & & & & & & \\
\hline Consistency & 5 & Core Value & $0.503^{\text {*** }}$ & 0.574 ** & $0.635^{* * *}$ & $0.510^{\text {** }}$ & & & & & & & & \\
\hline \multirow[t]{3}{*}{ Ad ap tability } & 8 & Creating Change & 0.652 ** & 0.673 ** & $0.647 * *$ & 0.353 ** & $0.538 * *$ & $0.555^{\text {** }}$ & 0.513 ** & & & & & \\
\hline & 9 & Customer Focus & $0.332 *$ & $0.456^{\text {** }}$ & $0.501^{* *}$ & 0.162 & $0.484^{* *}$ & $0.506^{* *}$ & 0.570 决 & $0.407^{\text {*** }}$ & & & & \\
\hline & 10 & Org anis at ional Learning & $0.312^{*} *$ & $0.581^{\text {** }}$ & $0.632^{\text {*** }}$ & $0.329^{\text {粬 }}$ & $0.491^{* *}$ & 0.378 ** & $0.506^{\text {** }}$ & $0.476^{\text {*** }}$ & $0.468^{\text {** }}$ & & & \\
\hline \multirow[t]{2}{*}{ Mission } & 11 & Strateg ic Direction \& Inte & $0.525^{\text {米 }}$ & $0.576^{\text {䊑 }}$ & 0.652 ** & $0.389^{\text {w* }}$ & 0.658 *** & $0.540^{\text {** }}$ & $0.619^{\text {冰 }}$ & $0.613^{\text {* }}$ 米 & $0.486^{* *}$ & $0.497^{* *}$ & & \\
\hline & 12 & Goals and Objectives & $0.471^{\text {** }}$ & $0.654 * *$ & $0.681^{* *}$ & $0.429^{\text {** }}$ & 0.696 * & $0.603^{\text {** }}$ & $0.581^{\text {*** }}$ & $0.584^{\text {** }}$ & $0.537^{\text {*** }}$ & $0.478 * *$ & $0.715^{\text {** }}$ & \\
\hline
\end{tabular}

building organisational learning, and creating change). This may be more appropriate than focusing on consistency attributes (enhancing greater coordination and control or building and refining existing systems), which appear more attuned to the needs of organisations operating in a stable environment. 
Multiple regression was then used to indicate how much of the variance in business performance can be explained by each cultural trait. Given the sample size is smaller than normally desirable for multiple regression, the results need to be reviewed with caution, so the adjusted R Square was used as it is a more accurate estimate of the influence of each trait on business performance (Anderson $e t$ $a l, 1999)$. Results showed that 44 percent of business performance variations could be explained by creating change (a subcomponent of adaptability) (See Table 8). The sub-components of business performance were broken down further to help identify which cultural traits explained their variations. This analysis identified that creating change (subcomponent of adaptability) was a major influence in all areas of business performance explaining 18 percent of net profit variations, 24 percent of market share variations, and 23 percent of sales trends. It was also a major factor in explaining return on investment, efficiency trend, and customer satisfaction variations (See Table 8).

When looking at the results of high performing organisations versus low performing organisations, one of the key findings was that all large organisations surveyed could be categorised as low performing organisations.

\section{Table 8. Summary of Relationship between Business Performance and Cultural Traits}

\begin{tabular}{|l|c|c|}
\hline P Value & R Square & Creating Change \\
\hline Business Performance & .44 & 0 \\
\hline Net Profit & .18 & 0 \\
\hline Customer Satisfaction & .31 & .003 \\
\hline Market Share & .24 & 0 \\
\hline Return on Investment & .35 & .003 \\
\hline Efficiency trend & .38 & .011 \\
\hline Sales Trend & .23 & 0 \\
\hline
\end{tabular}

The following paragraphs further outline these findings and potential implications in achieving high performance (See Table 7) for a detailed summary of the mean scores for all cultural traits and their subcomponents). It should be noted that the mean provided immediately after each trait subcomponent heading refers to the mean for the eighty organisations in this survey.

\section{Consistency Trait}

Respondents' opinions that consistency is the most important cultural trait, suggests their belief that a key to business success is to develop and maintain core values, have clear methods to reach agreement on issues, and maintain clear coordination and integration systems. Yet the study identified that this trait is least likely to lead to increased performance. Closer analysis of the subcomponents of this trait revealed that high performing small to medium firms did things differently to low performing firms.

When it comes to core values (See Table 9), we found that small to medium high performing firms were more likely to demonstrate core values through having leaders and managers who promote their core values such as "practicing what they preach"; using a distinct management style and setting a clear code of practice, whilst conducting business in an ethical manner.

High performing small to medium firms were more likely to work hard to achieve win-win solutions when disagreements occurred; tended to reach agreement by consensus; and generally had clear agreement on the right and wrong way to do things, all within a strong culture. Interestingly, we found that low-performing small to medium firms were less likely to dispute key issues, suggesting top management decisions are perhaps not open for debate and criticism.

Related to coordination and integration, we found that high performing small to medium firms were 
more likely to have a consistent and predictable approach to business. They easily coordinate projects across the organisation. Such firms have the employees who feel comfortable working in cross-functional teams, sharing common perspective, and ensuring there is good alignment of goals across all areas of the business.

\section{Adaptability Trait}

The comparatively lower score of adaptability in the overall results indicates that the Australian automobile industry may not yet recognise the importance of adapting to environmental change in order to improve it business performance (Pennington, 2003). Adaptability is often considered as a key strength of firms that are able to make decisions quickly and be flexible.

Respondents confirmed the importance of creating change to business performance in their organisations as found in previous study of Nwokah and Maclayton (2006). However, although this trait is identified as the most important one to achieve high performance, it is ranked lower than expected by respondents. A common response is that their organisations are not very interested in being innovative. Some respondents stated that this was due to the lack of delegated power to be innovative; lack of appropriate resources, in particular financial resources; and the failure by many organisations to provide an appropriate reward system to encourage innovation.

A higher score for creating change may be an indicator of an organisational core competence (Ljungquist 2007). However, given the current perception by respondents that adaptability's influence on business performance is lower than other factors, even though incorrect, it may be that some organisations do not understand the importance of developing creating change as potential core competency in a competitive environment. This situation appears to be typical for firms with small margins and lack of funding for innovation.

\section{Table 9. Detailed Summary of the Mean Scores for all Cultural Traits and their Subcomponents}

\begin{tabular}{|l|c|c|c|c|c|c|}
\hline & Total Firms & Total SMEs & $\begin{array}{c}\text { SMEs } \\
\text { HP }\end{array}$ & $\begin{array}{c}\text { SMEs } \\
\text { LP }\end{array}$ & $\begin{array}{c}\text { Large } \\
\text { Firms }\end{array}$ & $\begin{array}{c}\text { Summated } \\
\text { Mean } \\
\text { Difference }\end{array}$ \\
\hline Consistency & 3.76 & 3.82 & 3.99 & 3.58 & 3.3 & 20.5 \\
\hline Core Value & 4.1 & 4.14 & 4.35 & 3.86 & 3.66 & 24.5 \\
\hline Agreement & 3.65 & 3.75 & 3.97 & 3.45 & 3.03 & $\mathbf{2 6 . 0}$ \\
\hline Coordination and Integration & 3.54 & 3.58 & 3.68 & 3.44 & 3.2 & 12.0 \\
\hline Adaptability & 3.64 & 3.66 & 3.81 & 3.47 & 3.41 & 17.0 \\
\hline Creating Change & 3.77 & 3.81 & 4.06 & 3.46 & 3.4 & $\mathbf{3 0 . 0}$ \\
\hline Customer Focus & 3.59 & 3.58 & 3.68 & 3.45 & 3.6 & 11.2 \\
\hline Organisational Learning & 3.56 & 3.6 & 3.67 & 3.5 & 3.23 & 8.5 \\
\hline Mission & 3.77 & 3.81 & 3.97 & 3.6 & 3.31 & 18.5 \\
\hline Strategic Direction & 3.7 & 3.76 & 3.98 & 3.48 & 3 & 25.0 \\
\hline Goals and Objectives & 4.02 & 4.05 & 4.23 & 3.81 & 3.63 & 21.0 \\
\hline Vision & 3.59 & 3.62 & 3.71 & 3.51 & 3.29 & 10.0 \\
\hline Involvement & 3.87 & 3.9 & 4.05 & 3.69 & 3.59 & 18.0 \\
\hline Empowerment & 3.98 & 4.02 & 4.21 & 3.75 & 3.57 & 23.0 \\
\hline Team Orientation & 4.06 & 4.09 & 4.28 & 3.83 & 3.77 & 22.5 \\
\hline Capability Development & 3.57 & 3.58 & 3.67 & 3.46 & 3.43 & 10.5 \\
\hline
\end{tabular}

*SMEs-small to medium firms; **HP- high performing firms, ***LP - low performing firms

Further analysis identified that high performing firms were more likely than low performing organisations to do things in a flexible, easy to change way; they respond well to competitors and 
other changes in the business environment; they adopt innovative ways to work. In such organisations, different sectors cooperate to create change.

Interestingly, through the interviews we found that low performing organisations were less resistant to change than high performing ones. Although this finding might seem surprising, it could also suggest low performing organisations may jump on each new opportunity to improve short-term performance, rather than build a long-term strategic direction.

Customer focus is seen by respondents to have a lesser influence on performance than other factors (See Table 9). This finding obviously conflicts with Allen and Helms (2002) who argue that customer satisfaction is critical for business success. Further analysis identified that although most organisations understand the link between customer focus and business performance, many respondents find unnecessary for all employees to have knowledge of their customer's needs; rather they need to have relevant knowledge to do their jobs. This finding suggests a potential dilemma for organisations to decide what level of customer knowledge their employees need to have. We found that in high performing firms, employees were encouraged to have direct contact with customers, to listen and act on customer comments; and have a deep understanding of customer wants and needs.

In accordance with Hyland et al. (2001), the respondents identified organisational learning as significant for business performance, but not very important as other factors are. In our study it did not rank highly compared to other factors. Many respondents state that full benefit of a learning organisation is not achievable because of the existing not stimulating reward systems.

According to our research results, the high performing firms are more likely to regard failure as an opportunity for learning. They encourage and reward innovation and risk taking. They also regard learning as an important objective in day-to-day work.

\section{Mission Trait}

Given the current economic situation, a slightly lower ranking of mission compared to other traits was not surprising.

From the point of view of strategic direction, we found that high performing organisations are more likely to have long-term purpose and goals linked to an overall strategy. They have mission with clear meaning and direction to pursue business activities, indicating an intention to be the industry leader.

Interestingly, the respondents from the low performing firms have more clear strategic direction than high performing firms, although they have less capacity to effectively follow that direction.

When it comes to goals and objective, the high performing firms are more likely to have agreed goals by all employees. They have leaders who publically declare their ambitious and realistic goals, and continuously track progress against goals.

Further, we found that high performing firms are more likely to have shared vision that creates excitement and motivation for employees; thus indicating the employees' involvement in the planning process. Their leaders have defined that long-term goals meet short-term demands without compromising long-term vision.

\section{Involvement Trait}

Involvement was considered very important by respondents, yet multiple regression identified it had little to do with explaining changes in business performance (See Table 7). Analysis between high performing firms and low performing firms identified the differences in empowerment, team orientation and capability development.

High performing firms motivate their employees to achieve superior results by making decisions at the level with the best available information, information sharing, and having an inclusive and ongoing business planning process. Further, high performing firms have organisational structure based 
on teams. Thus, they encourage cooperation across the organisation through teamwork and they delegate authority, allowing the employees to act on their own. Recognizing capabilities of their employees as an important competitive advantage, these firms continually invest in improving their employees' skills.

Overall, the respondents' consideration of consistency as the highest importance of cultural traits to achieving high performance is not in accordance with our findings. We have found that automotive organisations may increase their organisational performance by paying more attention to adaptability attributes, and in particular to creating change through doing things in a flexible, easy to change way; responding well to competitors and other changes in the business environment; adopting innovative ways to work; and encouraging cooperation between different parts of the organisation.

From the point of view of high performing organisations and low performing organisations we found that the two variables with the greatest summated means difference were creating change (30.0) and gaining agreement (26.0). This finding is consistent with the findings of multiple regression analysis and further demonstrates the importance of firms being adaptable in times of rapid change.

\section{CONCLUSIONS}

The research project has revealed a link between corporate culture and business performance in the Australian automobile industry. Adaptability to environmental changes seems to be the key to sustainable business performance. This suggests that, the organisations should focus on all four cultural traits: involvement, consistency, adaptability and mission, as each plays an important, different and integrated role in achieving business performance outcomes.

Since the adaptability is identified as a key factor in enhancing business performance, a message to the Australian automotive industry is to concentrate on creating change, build strong customer focus, and become learning organisations. Low performing firms need to create an environment that encourages change, adopt new ways to do work, and improve teamwork.

When it comes to involvement, companies should encourage team orientation and employees' empowerment.

For mission trade, the companies' goal setting should include employees' participation in the planning process.

Finally, for consistency trait improvement, companies should act mote ethically.

Future research could focus on both internal and external environmental factors affecting business performance, their measurement and use to gain a sustainable competitive advantage. 


\section{REFERENCES}

Allen, R. S. and Helms, M. M. (2002) Employee perceptions of the relationship between strategy, rewards and organisational performance, Journal of Business Strategies, 19(2): 115-140.

Anderson, D .R., Sweeney, D. J and Williams, T.A. (1999) Statistics for Business and Economics, London: South-Western College Publishing.

Australian Bureau of Statistics (2002) 1321.0 - Small Business in Australia, 2001, Available at http:// www.abs.gov.au/ausstats/abs@.nsf/productsbytopic/97452F3932

F44031CA256C5B00027F19? OpenDocument [1 May 2009].

Bloodgood, J. M. and Katz. J.P. (2004) Manufacturing capacity, market share and competitiveness, Competitiveness Review: An International Business Journal incorporating Journal of Global Competitiveness, 14(1): 60-71.

Buckingham, M. (2005) The One Thing You Need to Know about Great Managing, Great Leading and Sustained Individual Success, New York: Free Press.

Creswell, J. W. (2003) Research design: Qualitative and Quantitative Mixed-Method Approaches. Thousand Oaks: Sage Publications.

Denison, D. R. and Neale, W.S. (1996) Denison organisational culture survey, Ann Arbor, MI: Aviat.

Denison, D. R., Haaland, S. and Goelzer,P. (2003) Corporate culture and organisational effectiveness: is there a similar pattern around the world?, Advances in Global Leadership, 3(2): 205 $-227$.

Department of Foreign Affairs and Trade (2008) Review of Australia's Automobile Industry 2008.

Hsu, Y. L., Lee, C. H., Chih, W. H. and Chiu, T.Y. (2009) Organisational learning as an intervening in the life insurance industry, The Business Review, 12(1): 174-186.

Hubbard, G. (2009) Measuring organisational performance: beyond the triple bottom line, Business Strategy and the Environment, 18, 177-191.

Hyland, P. W., Gieskes, J. F. and Sloan, T.R. (2001) Occupational clusters as determinants of organisational learning in the product innovation process, Journal of Workplace Learning, 13(5): 198-208.

Johnson, R. L. (2009) Organisational motivations for going green or profitability versus sustainability, Business Review, 13(1): 22-28.

Kennerley, M. and Neely, A. (2003) Measuring performance in a changing business environment, International Journal of Operations \& Production Management, 23(2):213-229.

Kloot, L. (1999) Performance measurement and accountability in Victorian local government, International Journal of Public Sector Management, 12(7): 565-583.

Lee, S. K. J. and Yu, K. (2004) Corporate culture and organisational performance, Journal of Managerial Psychology, 19(4): 340-359.

Liu, Y. and Zumbo, B.D. (2007) The impact of outliers on Cronbach's Coefficient Alpha estimate o reliability: visual analogue scales, Educational and Psychological Measurement, 67(4): 620-634.

Ljungquist, U. (2007) Core competency beyond identification: presentation of a model, Management Decision, 45(3): 393-402. 
Mavondo, F. and Farrell, M. (2003) Cultural orientation: its relationship with market orientation, innovation and organisational performance, Management Decision, 41(3): 241-249.

Nwokah, N. G. and Maclayton, D.W. (2006) Customer-focus and business performance: the study of food and beverage organisations in Nigeria, Measuring Business Excellence, 10(4): 65-76.

Pennington, G. (2003) Guidelines for Promoting and Facilitating Change. LTSN Generic Centre. Available at http://www.jiscinfonet.ac.uk/infokits/change-management/lessons-he-sector [20 December 2008].

Petrovic-Lazarevic, S. (2006) Knowledge, culture change in organisations and competitive advantage: the case of construction industry corporations in Australia, International Journal of Knowledge, Culture and Change in Organisations, 5(1): 11-19.

Robert, K. (2000) Tools and concepts for sustainable development: how do they relate to a general framework for sustainable development, and to each other, Journal of Cleaner Production, 8(3): 243 -254 .

Rotenberry, P. F. and Moberg, P.J. (2007) Assessing the impact of job involvement on performance, Management Research News, 30(3): 203-215.

Scholtens, B. (2009) Corporate social responsibility in the international banking industry, Journal of Business Ethics, 86(2): 159-175.

Sellitto, C. (2006) Improving winery survey response rates: lessons from the Australian wine industry, International Journal of Wine Marketing, 18(2): 150-152.

Singh, S. (2006) Cultural differences in and influences on consumers' propensity to adopt innovations, International Marketing Review, 23(2): 173-191.

Van Marrewijk, M. And Werre, M. (2003) Multiple levels of corporate suitability, Journal of Business Ethics, 44(2/3): 107-119.

Vukmir, R. B. (2006) Customer satisfaction, International Journal of Health Care Quality Assurance, 19(1): 8-31. 